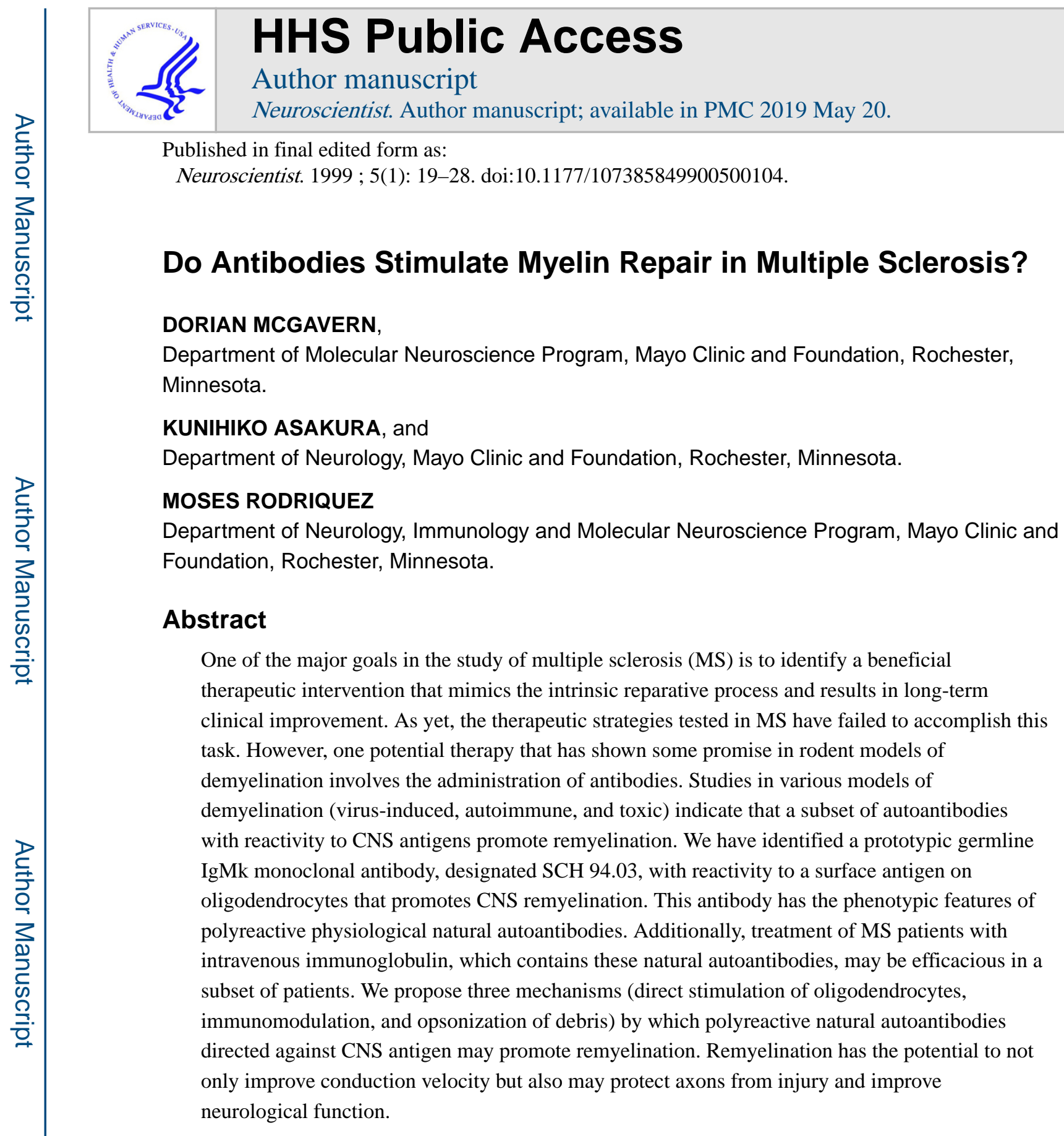

\title{
Keywords
}

Remyelination; Theiler's virus; Autoantibodies; Oligodendrocytes

Multiple sclerosis (MS) is the most common inflammatory demyelinating disease in humans and is predominately characterized by damage to the oligodendrocytes and myelin in the CNS. Lesions, commonly referred to as plaques, are scattered throughout the CNS and contribute, at least in part, to the clinical deficits observed in patients (1). At present, the cause of MS is unknown and no cure is currently available. In an effort to improve or

Address reprint requests to: Moses Rodriguez, M.D., Mayo Clinic, 200 First Street SW, Rochester, Minnesota 55905 (rodriguez.moses@mayo.edu). 
preserve neurological function in patients with MS, a number of therapeutic strategies have been attempted with limited success. Most of these approaches are based on the hypothesis that the immune system contributes to the pathogenesis and the target antigen is a host protein in the CNS. In light of this limited success, it is of great importance to accelerate research leading toward a beneficial therapeutic intervention.

It is unknown why MS patients present with varying degrees of neurological deficit and respond differently to therapeutic strategies. The most logical explanation is to assume that a correlation exists between the severity of clinical dysfunction and the location and number of demyelinated plaques. However, this argument is confounded by evidence of patients with no neurological deficits and severe demyelination found at autopsy $(2,3)$. Recently, Lucchinetti et al. (4) have provided an alternative explanation, suggesting that the pathogenesis of myelin destruction and subsequent axonal injury in MS may be heterogeneous and that a variety of immunological mechanisms may contribute to a common endpoint, demyelination. This heterogeneity of pathogenesis may very well explain some of the variability observed in the progression of MS and the response to therapeutic strategies.

\section{Remyelination in MS}

The variable presentation of symptoms combined with the unknown etiology of MS makes therapeutic intervention challenging. However, because demyelination is the common endpoint in the disease, strategies that promote remyelination and prevent axonal injury will most likely be of some clinical benefit. Although ultrastructural analysis of MS lesions indicate that oligodendrocytes are significantly decreased in the chronic stages of disease, it is evident that the potential exists for remyelination in many acute lesions (5). Furthermore, enhancement of the remyelination process through therapeutic intervention may promote the preservation of oligodendrocytes and axons, and maintain neurological function in the chronic stages of disease.

Studies indicate that remyelination by both oligodendrocytes (6-9) and Schwann cells (10, 11) can occur in MS lesions, yet it seems that this reparative process is never complete. In rodent models of demyelination, involving the use of such toxic agents as ethidium bromide (12) or lysolecithin (13), direct toxicity to the oligodendrocyte or the myelin is followed by complete remyelination. These models differ from MS in that they lack the involvement of the immune response. This suggests that in the CNS, remyelination is a natural reparative function after demyelination $(14,15)$, yet a persistent immune response, such as the one observed in MS, can interfere with the process.

Theoretically, the absence of remyelination observed in MS may be caused either by a direct failure of the remyelinating process or by an inhibition of factors that promote remyelination. In either case, a number of intrinsic mechanisms for remyelination have been proposed (1). These include: 1) the production of growth factors by astrocytes or neurons that contribute to oligodendrocyte survival, proliferation, and differentiation, 2) the dedifferentiation of oligodendrocytes to an immature progenitor phenotype capable of proliferation, 3) the depletion of pathogenic lymphocytes by regulatory T cells, and 4) the 
production by B cells of autoantibodies that promote remyelination. It is the latter mechanism that is of significant interest to our laboratory.

\section{Natural Autoantibodies Promote Remyelination in Experimental Models of Demyelination}

To determine whether the autoreactive humoral response was pathogenic or protective in a chronic immune-mediated disease process, we used the Theiler's murine encephalomyelitis virus (TMEV) model of MS. TMEV is a picomavirus that induces a chronic, progressive inflammatory CNS demyelinating disease in susceptible strains of mice (16). After the induction of chronic TMEV infection, the demyelination observed is pathologically indistinguishable from MS $(17,18)$, and the episodes of demyelination are recurrent (19). The pathogenesis of demyelination has been determined to be immune-mediated $(16,20)$, and only a minimal amount of spontaneous remyelination has been observed in the demyelinated lesions of susceptible mice (21). This provides an excellent model for the identification of therapeutic strategies that promote remyelination rather than induce demyelination.

Initially, Traugott et al. (22) discovered a beneficial immune response in guinea pigs with the prototypic T cell-mediated model of MS, experimental autoimmune encephalomyelitis (EAE). Animals injected with myelin basic protein (MBP) and galactocerebroside (GC) in incomplete Freund's adjuvant, either early or late after the induction of disease, were noted as having fewer or no clinical relapses for more than a year after treatment. Upon further examination, extensive remyelination and oligodendrocyte proliferation were observed in the lesions of the treated animals. These results were confirmed in a second model of immunemediated demyelination by Lang et al. (23) when CNS remyelination was observed in TMEV-infected SJL/J mice injected with MBP/GC in incomplete Freund's adjuvant. Both studies provided data suggesting that it was possible to stimulate a beneficial humoral response.

To directly implicate the humoral response as having a positive effect in demyelinating disease, uninfected SJL/J mice were injected with normal syngeneic spinal cord homogenate $(\mathrm{SCH})$ to generate hyperimmune serum. The antiserum was then passively transferred into chronically TMEV-infected SJL/J mice (24). After 4-5 weeks of treatment, a tenfold increase in the area of remyelination and a decrease in inflammation were observed in spinal cord lesions. In a subsequent study, passive transfer of purified IgG from the hyperimmunized mice described above also induced a sixfold increase in remyelination for chronically infected mice (25). In addition, morphological and immunohistochemical analyses indicated that proliferating cells expressing oligodendrocyte-specific markers (possibly progenitors) were present in the remyelinated lesions (Fig. 3). These studies demonstrated that antibodies directed against self-antigens could, in fact, promote remyelination.

We next generated a panel of monoclonal antibodies derived from splenocytes of SJL/J mice injected with SCH and screened them for their ability to bind autoantigens and promote remyelination (26). This selection of autoantibodies based on functional characteristics 
resulted in the production of a monoclonal $\operatorname{IgM}_{\kappa}$ (designated SCH 94.03) that promoted fourfold more remyelination in chronically-infected SJL/J mice than did IgM or buffer controls (Fig. 1, A-F). In this study, it was also determined that SCH 94.03 recognized both surface and cytoplasmic antigens on glial cells (Fig. 1 G-I).

To further characterize SCH 94.03, subsequent studies from our laboratory reported the binding patterns, potential mechanisms of action, and clinical benefits of SCH 94.03 in other experimental models of demyelinating disease. Initially, it was determined that $\mathrm{SCH} 94.03$ was encoded by the germline Ig light chain $\mathrm{V}_{\mathrm{k}} 10 / \mathrm{J}_{\mathrm{k}} 1$ and heavy chain $\mathrm{V} 23 / \mathrm{DFL} 16.1 / \mathrm{J}_{\mathrm{H}} 2$ genes with no definitive somatic mutations (27). It was also shown in this same report that SCH 94.03 exhibited polyreactivity toward several protein antigens (including spectrin, tubulin, and actin) and chemical haptens. This led to the conclusion that SCH 94.03 was a natural autoantibody capable of inducing remyelination.

As described above, the autoreactive binding patterns of SCH 94.03 are extremely broad (28-30). By screening a rat cDNA library from the CNS, it was shown that SCH 94.03 reacts with multiple known proteins and at least four unique and previously undescribed antigens (30). It has been reported that within the CNS, SCH 94.03 labels fibrous astrocytes, ependymal cells, ganglion satellite cells, and a subpopulation of microglia, oligodendrocytes, and peripheral nervous system neurons; outside the CNS, SCH 94.03 labels gastrointestinal smooth tract muscle and luminal epithelium, erythrocytes, and interdigitating dendritic cells in peripheral lymphoid organs (28). More specifically, after being stained with $\mathrm{SCH} 94.03$, rat and mouse oligodendrocytes have shown strong surface reactivity that does not result from reactivity to lipid (29). Approximately $50 \%$ of the cells that stain positively with SCH 94.03 express MBP (a marker of mature oligodendrocytes) (Fig. 1, G-I), whereas all oligodendrocyte progenitors were negative for surface staining. This pattern suggests that an oligodendrocyte-specific $\mathrm{SCH} 94.03$ antigen may be developmentally regulated.

\section{Potential Mechanisms of Action for Remyelination-promoting Autoantibodies}

The broad polyreactivity of SCH 94.03 presents a considerable challenge when attempting to elucidate the mechanism(s) by which this natural autoantibody promotes remyelination. It is easiest to assume that the remyelination-promoting properties of $\mathrm{SCH} 94.03$ relate to the oligodendrocyte surface reactivity. However, in light of the broad spectrum of antigens to which SCH 94.03 binds, it is possible that the function of SCH 94.03 and other remyelination-promoting autoantibodies may relate to their reactivity to other cell types.

Figure 2 depicts three potential mechanisms by which remyelination-promoting autoantibodies could function. These include 1) direct stimulation of the oligodendrocyte, 2) immunomodulation, and 3) the "scavenger" hypothesis. These autoantibodies may employ one or several of the mechanisms described to promote remyelination. 


\section{Direct Stimulation of Oligodendrocytes}

It has been shown that antibodies are capable of directly stimulating oligodendrocyte activity in vitro (31-34). This direct stimulation may promote oligodendrocyte survival and differentiation. Previous studies indicated that antiserum or purified IgG directed against $\mathrm{SCH}$ is capable of inducing proliferation of oligodendrocytes both in vitro (24) and in vivo (Fig. 3). In vivo treatment also resulted in a three- or fourfold increase in the expression of proteolipid protein in the CNS (35). Additionally, SCH 94.03 is capable of inducing the proliferation of mixed glial cell cultures in vitro (Miller DJ, Rodriguez M, unpublished observations). It therefore seems possible that natural autoantibodies may trigger signaling pathways in oligodendrocytes or indirectly promote proliferation by modulating the immune response.

\section{Immunomodulation}

Natural autoantibodies are thought to represent a substantial fraction of the immunoglobulin repertoire (36) and possess the ability to modulate the function of the immune system (37). Studies indicate that natural autoantibodies can suppress antibody responses to the acetylcholine receptor in an animal model of myasthenia (38) and prevent the development of diabetes in the nonobese diabetic (NOD) mouse (39). Interestingly, treatment of chronically-infected SJL/J mice with SCH 94.03 resulted in a two- to threefold reduction in the number of $\mathrm{CD}^{+}$and $\mathrm{CD}^{+} \mathrm{T}$ cells infiltrating the $\mathrm{CNS}$ and a suppression of the humoral immune response to a $\mathrm{T}$ cell-dependent antigen (40). The treatment also resulted in a two- to threefold increase in viral titers, which indicates that the remyelination-promoting properties of SCH 94.03 are not caused by decreased viral load. There is also evidence that immunosuppression of virus-infected mice with cyclophosphamide or by depletion of CD4 ${ }^{+}$ or $\mathrm{CD} 8^{+} \mathrm{T}$ cells with monoclonal antibody therapy also enhances remyelination (41). Together, the studies support the concept that manipulation of the immune response will influence the capacity for remyelination.

Additional evidence in support of the immunomodulatory role of natural autoantibodies was provided in a study that assessed the effects of SCH 94.03 treatment in mice with EAE (42). Treatment with SCH 94.03 after recovery from the initial episode of clinical disease resulted in a 50\% reduction in the relapse rates, prolonged relapse onset, and reduced spinal cord demyelination and meningeal inflammation. These results support previously mentioned findings in that they demonstrate that natural autoantibodies may promote remyelination by modulating the immune response.

\section{"Scavenger" Hypothesis}

As mentioned previously, natural autoantibodies are typically polyreactive, binding to a number of unrelated antigens (37). We have shown recently that several oligodendrocytereactive IgM monoclonal antibodies with distinct antigen specificities promote remyelination in chronically infected SJL/J mice (42a). It is therefore possible that autoantibodies capable of promoting remyelination do so by aiding in the removal of cellular debris from the demyelinated lesion. This may explain why autoantibodies that promote remyelination are reactive to intracellular cytoskeletal antigens. Opsonization of debris by polyreactive autoantibodies may accelerate dissipation of the cellular infiltrate from a 
demyelinated lesion and limit the amount of significant damage to progenitor and mature populations of oligodendrocytes. The expeditious clearance of debris from the lesion would then allow the intrinsic reparative process of remyelination to engage without inhibition. This mechanism explains both the decreased inflammatory response and the predominance of proliferating oligodendrocytes in the lesions after treatment with autoantibodies directed against $\mathrm{SCH}$.

This explanation is supported by the fact that immunoglobulins directed against MBP promote remyelination in chronically-infected SJL/J mice (43) (Fig. 4). MBP is not expressed on the surface of oligodendrocytes, which argues against the direct stimulation of oligodendrocytes as the mechanism for the remyelination-promoting activity of antibodies to MBP. These antibodies may aid in the clearance of debris. The fact that immunoglobulins lacking CNS antigen specificity fail to induce remyelination indicates that targeting of antibodies to the lesion is necessary for repair. Additionally, it has been reported recently that $\mathrm{SCH} 94.03$ accelerates the remyelination process after the induction of demyelination by lysolecithin (44). Because both spontaneous remyelination and the absence of an immune response have been described in the lysolecithin model of demyelination (13), these results further implicate remyelination-promoting autoantibodies in the process of debris clearance.

\section{Role of Antibodies in MS}

Because it is has been shown in three rodent models of demyelination (virus-induced, autoimmune, and toxic) that natural autoantibodies can promote remyelination or limit clinical relapses, the question of whether these antibodies have the same effect in MS is of great importance. One of the hallmark signs of MS is the presence of oligoclonal bands in the CSF; these bands appear in more than $90 \%$ of patients with clinically defined MS (45). It has been assumed previously that the elevated levels of immunoglobulin in the CSF contribute to a pathogenic response in MS patients $(46,47)$. This is supported in part by observations in EAE where IgG antibodies to myelin-oligodendrocyte glycoprotein (MOG) enhanced demyelination $(48,49)$. At present, however, there is minimal direct evidence in human MS to support the role of immunoglobulins in the destruction of myelin. Furthermore, studies of oligoclonal bands in patients have resulted in no correlations between immunoglobulin synthesis and the progression of disease $(50,51)$. This leads to the alternative hypothesis that the presence of elevated antibody production in the CSF of MS patients represents an intrinsic and potentially beneficial response capable of promoting remyelination.

Natural autoantibodies are present in the serum of normal individuals, which sets them in a physiological rather than a pathogenic light. For example, natural autoantibodies with reactivity to skeletal proteins such as spectrin have been identified in healthy individuals (52). Moreover, it has been shown using hybridoma technology that lymphocytes from normal mice can make monoclonal autoantibodies that are reactive with multiple organs (53). These data correspond with the pattern of reactivity observed for the remyelinationpromoting autoantibody SCH 94.03 and suggest that autoantibodies with a similar function may be present in patients with MS as well as in normal individuals. 
It has been reported that the $\mathrm{Ly}-1^{+} \mathrm{B}$ lymphocyte in mice is responsible for the production of natural autoantibodies (54). The equivalent of the $\mathrm{Ly}-1^{+} \mathrm{B}$ cell in humans is referred to as the $\mathrm{CD} 5+\mathrm{B}$ cell. This distinct population of B cells was found to account for approximately $17 \%$ of the total normal B cell repertoire (55) and was shown to produce antibodies against the self rather than exogenous antigens (56). These studies collectively indicate that a specific subset of B cells that are CD5+ possesses the ability to produce polyreactive natural autoantibodies. Furthermore, because the remyelination-promoting antibody SCH 94.03 has also been determined to be a polyreactive natural autoantibody, these B cells may be the source of SCH 94.03 and other remyelination-promoting autoantibodies.

Studies indicate that $\mathrm{CD}^{+} \mathrm{B}$ cells are increased in the CSF of patients with MS $(57,58)$. In these studies, it was proposed that $\mathrm{CD}^{+} \mathrm{B}$ cells were pathogenic in MS as a result of their accepted role in autoantibody production. However, this may not be the case. Several groups have reported increased levels of CSF immunoglobulins in MS patients $(59,60)$, and it has also been shown that amongst these immunoglobulins are elevated levels of polyreactive autoantibodies (51). Interestingly, the staining patterns of MS serum also correspond with those of autoantibodies such as SCH 94.03. Traugott et al. (61) noted that MS sera stained oligodendrocytes positively, and studies conducted by Singh and Mashal (62) indicated that the staining pattern on glial cell cultures was either cytoplasmic or associated with the cell surface membrane. This is comparable with the staining pattern of the remyelinationpromoting autoantibody SCH 94.03 and is consistent with the hypothesis that remyelinationpromoting autoantibodies are present in patients with MS.

With each of these facts in mind, it seems reasonable to propose that a subset of natural autoantibodies promotes remyelination in MS. However, this does not exclude the possibility that antibodies with a unique specificity and isotype, such as those directed against MOG, contribute to myelin destruction. A subset of polyreactive natural autoantibodies with germline sequence may be responsible for promoting remyelination, whereas antibodies that undergo somatic mutation, experience isotype switching, and are reactive with specific antigens may contribute to a pathogenic response. The production of remyelinationpromoting natural autoantibodies may represent a physiological attempt to counteract the pathogenic response in MS.

Remyelination-promoting autoantibodies may function by aiding in the clearance of debris from lesions (Fig. 2), allowing the intrinsic reparative process of remyelination to proceed. A great number of macrophages and activated microglia are found in MS lesions (5, 63); these cells may be the effectors in the destruction of oligodendrocytes and myelin (64). Additionally, immunoglobulins have been detected on the surface and within the cytoplasm of macrophages clearing myelin from the (65). Therefore, the polyreactive binding of natural autoantibodies to debris within MS lesions may assist macrophages and microglia in efficiently clearing lesions and limit the amount of damage that myelin and, more importantly, axons accrue. 


\section{Therapeutic Benefit of Remyelination-promoting Antibodies in MS?}

In light of the facts that natural autoantibodies promote remyelination in three animal models of demyelination (virus-induced, autoimmune, and toxic) and elevated levels of natural autoantibodies are found in the CSF of MS patients, it is possible that this subgroup of antibodies is not detrimental to MS patients. Additional data supporting this argument are found in studies that have addressed the role of intravenous immunoglobulin (IVIg) in the treatment of MS. Pooled polyclonal immunoglobulin is obtained from normal human donors and has been shown to contain antibodies with multiple specificities, including natural autoantibodies (66). Several uncontrolled studies have indicated that treatment of MS patients with IVIg is beneficial (67-69). For example, van Engelen and colleagues observed that repeated administration of IVIg to MS patients with nonrecovering, steroidunresponsive optic neuritis resulted in an improvement of vision that lasted for the duration of the follow-up period (1.2-1.7 years) (69). It was suggested in this study that the long-term improvement possibly resulted from the induction of remyelination, because an improvement of various optic nerve functions was observed in some eyes. Additionally, this improvement of function did not correlate with the resolution of acute inflammation after treatment with methylprednisolone. More recently, a randomized placebo-controlled study found that monthly IVIg treatment of patients with relapse-remitting MS improved the course of clinical disability and reduced the frequency of relapses (70). Each of these studies indicates that antibody therapy is potentially beneficial in the treatment of MS.

Future directions in our laboratory are based on the hypothesis that there are natural autoantibodies within human serum that can promote remyelination in demyelinating disease. Isolation of natural human autoantibodies with the binding properties and remyelination-promoting abilities of SCH 94.03 may allow for a more refined treatment in patients with MS. Use of these antibodies in the treatment of MS patients will hopefully result in the long-term improvement of neurological function, emanating from the induction of remyelination and the subsequent preservation of axons.

\section{Acknowledgments}

These experiments were supported by the grants NS24180, NS32129, and AI-4-5197 from the National Institutes of Health. We also appreciate the financial support of Mr. and Mrs. Eugene Applebaum and Ms. Kathryn Peterson

\section{References}

1. Lucchinetti CF, Rodriguez M. The controversy surrounding the pathogenesis of the multiple sclerosis lesion. Mayo Clin Proc 1997;72:665-678. [PubMed: 9212772]

2. Gilbert JJ, Sadler M. Unsuspected multiple sclerosis. Arch Neurol 1983;40:533-536. [PubMed: 6615282]

3. Mackay RP, Hirano A. Forms of benign multiple sclerosis: Report of two "clinically silent" cases discovered at autopsy. Arch Neurol 1967;17:588-600. [PubMed: 6054893]

4. Lucchinetti CF, Bruck W, Rodriguez M, Lassman H. Distinct patterns of multiple sclerosis pathology indicates heterogeneity in pathogenesis. Brain Pathol 1996;6:259-274.. [PubMed: 8864283]

5. Rodriguez M, Scheithauer B. Ultrastructure of multiple sclerosis. Ultrastruct Pathol 1994;18:3-13. [PubMed: 8191643] 
6. Raine CS, Scheinberg L, Waltz JM. Multiple sclerosis: Oligodendrocyte survival and proliferation in an active established lesion. Lab Invest 1981;45:534-546. [PubMed: 7321526]

7. Ghatak NR, Leshner RT, Price AC, Felton WL. Remyelination in the human central nervous system. J Neuropathol Exp Neurol 1989;48:507-518. [PubMed: 2769306]

8. Prineas JW, Kwon EE, Goldenberg PZ, Ilyas AA, Quarles RF, Benjamins JA, et al. Multiple sclerosis: Oligodendrocyte proliferation and differentiation in fresh lesions. Lab Invest 1989;61:489-503. [PubMed: 2811298]

9. Prineas JW, Barnard RO, Kwon EE, Sharer LR, Cho ES. Multiple sclerosis: Remyelination of nascent lesions. Ann Neurol 1993;33:137-151. [PubMed: 8434875]

10. Ghatak NR, Hirano A, Doron Y, Zimmerman HM. Remyelination in multiple sclerosis with peripheral type myelin. Arch Neurol 1973;29:262-267. [PubMed: 4728187]

11. Itoyama Y, Webster HF, Richardson EP, Trapp BD. Schwann cell remyelination of demyelinated axons in spinal multiple sclerosis lesions. Ann Neurol 1983;14:339-346. [PubMed: 6195956]

12. Yajima K, Suzuki K. Demyelination and remyelination in the rat central nervous system following ethidium bromide injection. Lab Invest 1979;41:385-392. [PubMed: 502470]

13. Gregson NA, Hall SM. A quantitative analysis of the effects of the intraneural injection of lysophosphatidyl choline. J Cell Sci 1973;13:257-277. [PubMed: 4729938]

14. Ludwin SK. Chronic demyelination inhibits remyelination in the central nervous system. An analysis of contributing factors. Lab Invest 1980;43:382-387. [PubMed: 7442125]

15. Ludwin SK. Remyelination in the central nervous system and the peripheral nervous system. Adv Neurol 1988;47:215-254. [PubMed: 3278518]

16. Rodriguez M, Oleszak E, Leibowitz J. Theiler's murine encephalomyelitis: A model of demyelination and persistence of virus. Crit Rev Immunol 1987;7:325-365. [PubMed: 2827957]

17. Lehrich JR, Amason BGW, Hochberg FH. Demyelinative myelopathy in mice induced by the DA virus. J Neurol Sci 1976;29:149-160. [PubMed: 185333]

18. Dal Canto MC, Lipton HL. Multiple sclerosis. Animal model: Theiler's virus infection in mice. Am J Pathol 1977;88:497-500. [PubMed: 195474]

19. Dal Canto MC, Lipton HL. Recurrent demyelination in chronic central nervous system infection produced by Theiler's murine encephalomyelitis virus. J Neurol Sci 1979;42:391-405. [PubMed: 512673]

20. Yamada M, Zurbriggen A, Fujinami RS. Pathogenesis of Theiler's murine encephalomyelitis virus. Adv Vims Res 1991 ;39: 291-320.

21. Dal Canto MC, Lipton HL. Primary demyelination in Theiler's virus infection. Lab Invest 1975;33:626-637. [PubMed: 1202282]

22. Traugott U, Stone SH, Raine CS. Chronic relapsing experimental autoimmune encephalomyelitis. Treatment with combinations of myelin components promotes clinical and structural recovery. $\mathbf{J}$ Neurol Sci 1982;56:65-73. [PubMed: 6183403]

23. Lang W, Rodriguez M, Lennon VA, Lampert PW. Demyelination and remyelination in murine viral encephalomyelitis. Ann N Y Acad Sci 1984;436:98-102. [PubMed: 6085230]

24. Rodriguez M, Lennon VA, Benveniste EN, Merrill JE. Remyelination by oligodendrocytes stimulated by antiserum to spinal cord. J Neuropathol Exp Neurol 1987;46:84-95. [PubMed: 2432195]

25. Rodriguez M, Lennon VA. Immunoglobulins promote remyelination in the central nervous system. Ann Neurol 1990;27:12-17. [PubMed: 2301922]

26. Miller DJ, Sanborn KS, Katzmann JA, Rodriguez M. Monoclonal autoantibodies promote central nervous system repair in an animal model of multiple sclerosis. J Neurosci 1994;14:6230-6238. [PubMed: 7931575]

27. Miller DJ, Rodriguez M. A monoclonal autoantibody that promotes central nervous system remyelination in a model of multiple sclerosis is a natural autoantibody encoded by germline immunoglobulin genes. J Immunol 1995;154:2460-2469 [PubMed: 7868912]

28. Miller DJ, Njenga MK, Parisi JE, Rodriguez M. Multi-organ reactivity of a monoclonal natural autoantibody that promotes remyelination in a mouse model of multiple sclerosis. J Histochem Cytochem 1995;44:1005-1011. 
29. Asakura K, Miller DJ, Murray K, Bansal R, Pfeiffer SE, Rodriguez M. Monoclonal autoantibody $\mathrm{SCH} 94.03$, which promotes central nervous system remyelination, recognizes an antigen on the surface of oligodendrocytes. J Neurosci Res 1996;43:273-281. [PubMed: 8714516]

30. Asakura K, Pogulis RJ, Pease LR, Rodriguez M. A monoclonal autoantibody which promotes central nervous system remyelination is highly polyreactive to multiple known and novel antigens. J Neuroimmunol 1996;65:11-19. [PubMed: 8642059]

31. Lehrer GM, Maker HS, Silides DJ, Weiss C, Bomstein MB. Stimulation of myelin lipid synthesis in vitro by white matter antiserum in absence of complement. Brain Res 1979;172:557-560. [PubMed: 476499]

32. Bansal R, Gard AL, Pfeiffer SE. Stimulation of oligodendrocyte differentiation in culture by growth in the presence of a monoclonal antibody to sulfated glycolipid. J Neurosci Res 1988:21:260-267. [PubMed: 2464078]

33. Dyer CA, Benjamins JA. Galactocerebroside and sulfatide independently mediate $\mathrm{Ca} 2+$ responses in oligodendrocytes. J Neurosci Res 1991;30:699-711. [PubMed: 1787543]

34. Cohen JA, Williams WV, Geller HM, Greene MI. Anti-reovirus receptor antibody accelerates expression of the optic nerve oligodendrocyte developmental program. Proc Natl Acad Sci U S A 1991;88:1266-1270. [PubMed: 1705032]

35. Rodriguez M, Prayoonwiwat N, Howe C, Sanborn K. Proteolipid protein gene expression in demyelination and remyelination of the central nervous system: A model for multiple sclerosis. J Neuropathol Exp Neurol 1994;53:136-143. [PubMed: 7509847]

36. Rousseau PG, Malled CP, Smith-Gill SJ. A substantial proportion of the adult BALB/c available B cell repertoire consists of multireative B cells. Mol Immunol 1989;26:993-1006. [PubMed: 2594017]

37. Avrameas S, Ternynck T. The natural autoantibodies system: Between hypotheses and facts. Mol Immunol 1993;30:1133-1142. [PubMed: 8366863]

38. Sundblad A, Hauser S, Holmberg D, Cazenave PA, Coutinho A. Suppression of antibody responses to the acetylcholine receptor by natural antibodies. Eur J Immunol 1989;19:1425-1430. [PubMed: 2776827]

39. Andersson A, Forsgren S, Soderstrom A, Holmberg D. Monoclonal, natural antibodies prevent development of diabetes in the non-obese diabetic (NOD) mouse. J Autoimmun 1991;4:733-742. [PubMed: 1797023]

40. Miller DJ, Njenga MK, Murray PD, Leibowitz J, Rodriguez M. A monoclonal natural autoantibody that promotes remyelination suppresses central nervous system inflammation and increases virus expression after Theiler's virus-induced demyelination. Int Immunol 1996;8:131-141. [PubMed: 8671597]

41. Rodriguez M, Lindsley MD. Immunosuppression promotes central nervous system remyelination in chronic virus-induced demyelinating disease. Neurology 1992;42:348-357. [PubMed: 1736164]

42. Miller DJ, Bright JJ, Sriram S, Rodriguez M. Successful treatment of established relapsing experimental autoimmune encephalomyelitis in mice with a monoclonal natural autoantibody. $\mathrm{J}$ Immunol 1997;75:204-209.

42a. Asakura K, Miller DJ, Pease LR, Rodriguez M. Targeting of IgMr antibodies to oligodendrocytes promotes CNS myelination. J Neurosci 1998;18:7700-7708. [PubMed: 9742140]

43. Rodriguez M, Miller DJ, Lennon VA. Immunoglobulins reactive with myelin basic protein promote CNS remyelination. Neurology 1996;46:538-545. [PubMed: 8614528]

44. Pavelko KD, van Engelen BGM, Rodriguez M. Acceleration in the rate of central nervous system remyelination in lysolecithin-induced demyelination. J Neurosci 1998;18:2498-2505. [PubMed: 9502810]

45. Mehta PD, Miller JA, Tourtellotte WW. Oligoclonal IgG bands in plaques from multiple sclerosis brains. Neurology 1982;32:372-376. [PubMed: 7199659]

46. Link H, Baig S, Jiang YP, Olsson O, Hojeberg B, Kostulas V, et al. B cells and antibodies in MS. Res Immunol 1989;140:219-226. [PubMed: 2662285]

47. Warren KG, Catz I. Autoantibodies to myelin basic protein within multiple sclerosis central nervous system tissue. J Neurol Sci 1993;115:169-176. [PubMed: 7683331] 
48. Linington C, Engelhardt B, Kapocs G, Lassman H. Induction of persistently demyelinated lesions in the rat following the repeated adoptive transfer of encephalitogenic $\mathrm{T}$ cells and demyelinating antibody. J Neuroimmunol 1992;40:219-224. [PubMed: 1385471]

49. Schluesener HJ, Sobel RA, Linington C, Weiner HL. A monoclonal antibody against a myelin oligodendrocyte glycoprotein induces relapses and demyelination in central nervous system autoimmune disease. J Immunol 1987;139:4016-4021. [PubMed: 3500978]

50. Walsh MJ, Tourtellotte WW. Temporal invariance and clonal uniformity of brain and CSF IgG, IgA, and IgM in multiple sclerosis. J Exp Med 1986;163:41-53. [PubMed: 3941297]

51. Matsiota P, Blancher A, Doyon B, Guilbert B, Clanet M, Kouvelas ED, et al. Comparative study of natural autoantibodies in the serum and cerebrospinal fluid of normal individuals and patients with multiple sclerosis and other neurological diseases. Ann Inst Pasteur Immunol 1988;139:99-108.

52. Balias SK. Spectrin autoantibodies in normal human serum and in polyclonal blood grouping sera. Br J Haematol 1989;71:137-139. [PubMed: 2917121]

53. Prabhakar BS, Saegusa J, Onodera T, Notkins AL. Lymphocytes capable of making monoclonal autoantibodies that react with multiple organs are a common feature of the normal B cell repertoire. J Immunol 1984;133:2815-2817. [PubMed: 6333448]

54. Hayakawa K, Hardy RR, Honda M, Herzenberg LA, Steinberg AD. Ly-1 B cells: Functionally distinct lymphocytes that secrete IgM autoantibodies. Proc Natl Acad Sci U S A 1984;81:24942498. [PubMed: 6609363]

55. Casali P, Burastero SE, Nakamura M, Inghirami G, Notkins AL. Human lymphocytes making rheumatoid factor and antibody to ssDNA belong to Leu- ${ }^{1+}$ B-cell subset. Science 1987;236:7781. [PubMed: 3105056]

56. Casali P, Notkins AL. Probing the human B-cell repertoire with EBV: Polyreactive antibodies and CD5+ B lymphocytes. Ann Rev Immunol 1989;7:513-535. [PubMed: 2469441]

57. Mix E, Olsson T, Correale J, Baig S, Kostulas V, Olsson O, et al. B cells expressing CD5 are increased in cerebrospinal fluid of patients with multiple sclerosis. Clin Exp Immunol 1990;79:2127. [PubMed: 1689227]

58. Correale J, Mix E, Olsson T, Kostulas V, Fredrikson S, Hojeberg B, et al. CD5+ B cells and CD4-8- T cells in neuroimmunological diseases. J Neuroimmunol 1991;32:123-132. [PubMed: 1826505]

59. Nerenberg ST, Prasad R, Rothman ME. Cerebrospinal fluid IgG, IgA, IgM, IgD, and IgE levels in central nervous system disorders. Neurology 1978;28:988-990. [PubMed: 570668]

60. Williams AC, Mingioli ES, McFarland HF, Tourtellotte WW, McFarlin DE. Increased CSF IgM in multiple sclerosis. Neurology 1978;28:996-998.

61. Traugott U, Snyder DS, Raine CS. Oligodendrocyte staining by multiple sclerosis serum is nonspecific. Ann Neurol 1979;6:13-20. [PubMed: 389147]

62. Singh VK, Mashal RD. Immunofluorescent staining of rat brain glial cells with multiple sclerosis serum. Can J Neurol Sci 1981;8:143-145. [PubMed: 7028233]

63. Esiri MM, Reading MC. Macrophage populations associated with multiple sclerosis plaques. Neuropathol Appl Neurobiol 1987;13:451-465. [PubMed: 3328828]

64. Sriram S, Rodriguez M. Indictment of the microglia as the villain in multiple sclerosis. Neurology 1997;48:464-470. [PubMed: 9040740]

65. Prineas JW, Graham JS. Multiple sclerosis: Capping of surface immunoglobulin G on macrophages engaged in myelin breakdown. Ann Neurol 1981;10:149-158. [PubMed: 7025748]

66. Sundblad A, Marcos MA, Malanchere E, Castro A, Haury M, Huetz F, et al. Observations on the mode of action of normal immunoglobulin at high doses. Immunol Rev 1994;139:125-58. [PubMed: 7927409]

67. Achiron A, Pras E, Gilad R, Ziv I, Mandel M, Gordon CR, et al. Open controlled therapeutic trial of intravenous immune globulin in relapse-remitting multiple sclerosis. Arch Neurol 1992;49:1233-1236. [PubMed: 1449400]

68. Schuller E, Govaerts A. First results of immunotherapy with immunoglobulin $\mathrm{G}$ in multiple sclerosis patients. Eur Neurol 1983;22:205-212. [PubMed: 6861805] 
69. van Engelen BGM, Hommes OR, Pinckers A, Cruysberg JRM, Barkhof F, Rodriguez M. Improved vision after intravenous immunoglobulin in stable demyelinating optic neuritis. Ann Neurol 1992;32:834-835. [PubMed: 1471879]

70. Fazekas F, Deisenhammer F, Strasser-Fuchs S, Nahler G, Mamoli B. Randomised placebocontrolled trial of monthly intravenous immunoglobulin therapy in relapsing-remitting multiple sclerosis. Lancet 1997;349:589-593. [PubMed: 9057729] 

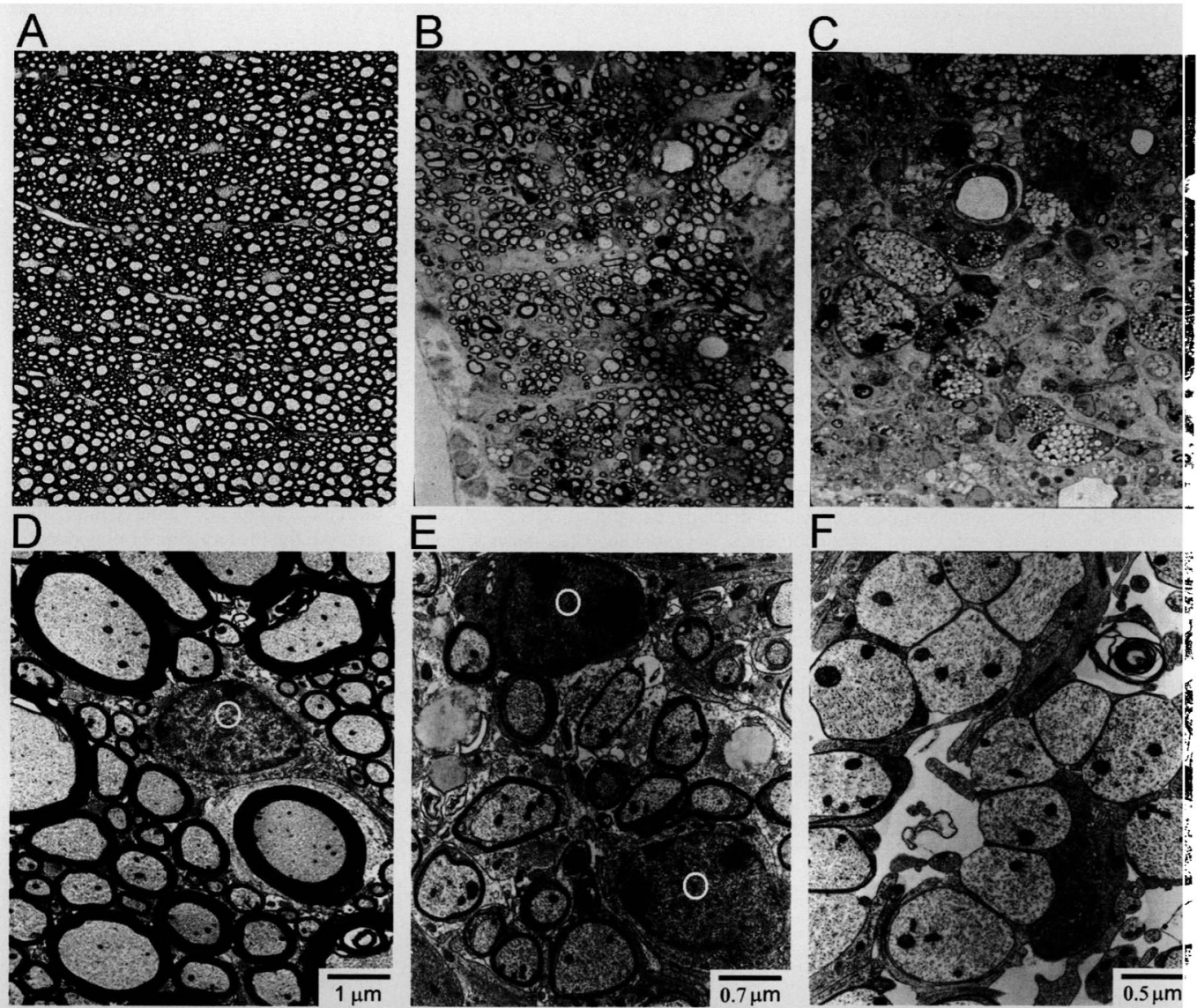

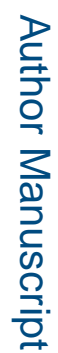

G
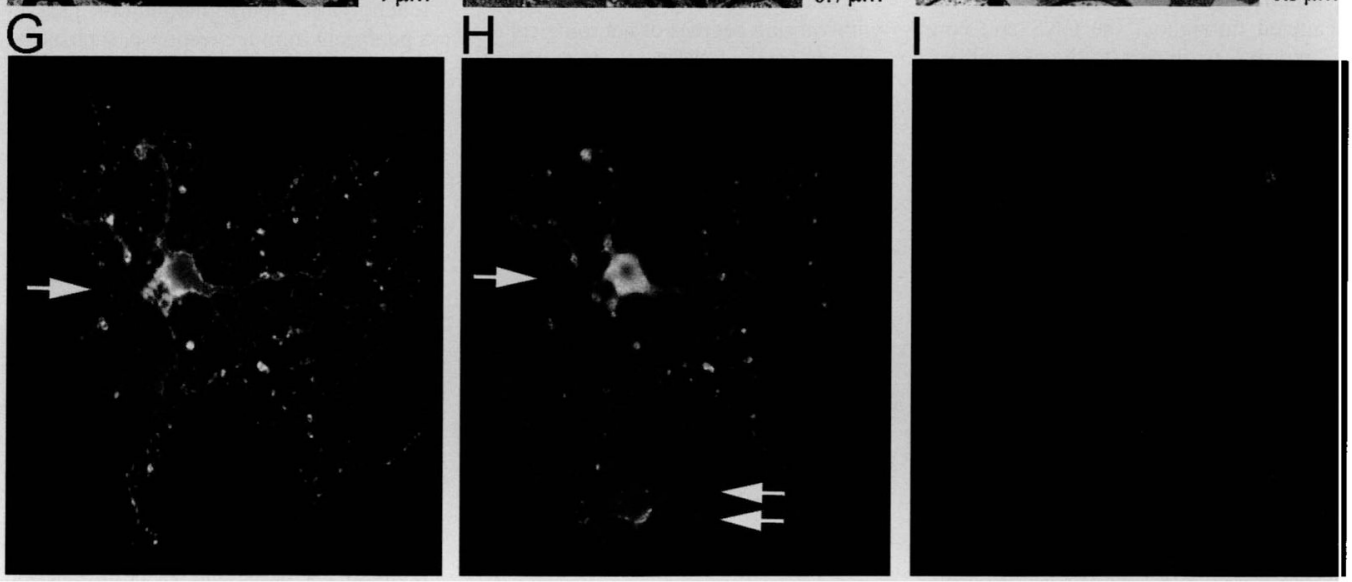

Fig. 1.

Promotion of remyelination and oligodendrocyte surface reactivity with the natural remyelination-promoting autoantibody designated as $\mathrm{SCH}$ 94.03. Spinal cord white matter photographs $(A, B, C)$ and electron micrographs $(D, E, F)$ are shown for uninfected $(A, D)$, chronically infected with Theiler's murine encephalomyelitis virus (TMEV) and treated with SCH $94.03(B, E)$, and chronically-TMEV-infected, untreated $(C, F)$ mice. Normal spinal cord white matter is shown for comparative purposes $(A, D)$. The electron dense material in $D$ corresponds to normal myelin surrounding axons. These dense rings of normal myelin are also apparent in $A$. In the chronic stages of disease, susceptible SJL/J mice normally show 
extensive demyelination with little or no remyelination. After treatment twice per week for 4-5 weeks (1 mg total dose) with SCH 94.03, extensive spinal cord remyelination results, as is evident by light $(B)$ and electron $(E)$ microscopy. Note the difference between the thinly remyelinated axons in $B$ and $E$ and the normally myelinated axons in A and D. SCH 94.03 treatment also increases the number of proliferating oligodendrocytes (white $O$ in $D$ and $E$ ) in the lesion, which then engage in the process of remyelination $(E)$. Chronically-infected $\mathrm{SJL} / \mathrm{J}$ mice treated with phosphate-buffered saline $(C)$ or a germline control IgM autoantibody $(F)$ continue to have extensive demyelination with little or no remyelination. (Original magnifications for $A-F$ are 900×, 900×, 1200×, 4000×, 6000×, and 7500×, respectively.) SCH 94.03 shows punctate labeling on the surface of oligodendrocytes in culture $(G)$. Approximately $50 \%$ of the SCH 94.03 positive cells in culture are positive for myelin basic protein (a marker for a mature oligodendrocyte) $(H) . G$ and $H$ are the same field, double-labeled with SCH 94.03 and an antibody to MBP. Note the cell (white arrow) labeled with both markers, whereas the MBP-positive cell (double white arrows) at the bottom of the figure does not label for the SCH 94.03 antigen. The germline control IgM that does not promote remyelination $(F)$ shows no reactivity on the surface of oligodendrocytes in culture ( $I$ ). (Original magnification for $G, H$, and $I$ is $500 \times$.) 
Direct Hypothesis

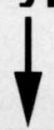

Stimulation of

Oligodendrocytes
Indirect Hypotheses

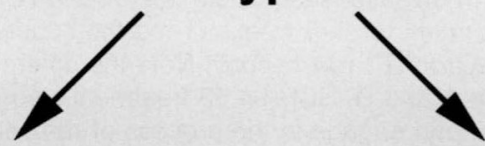

Immunomodulation
Opsonization of Debris

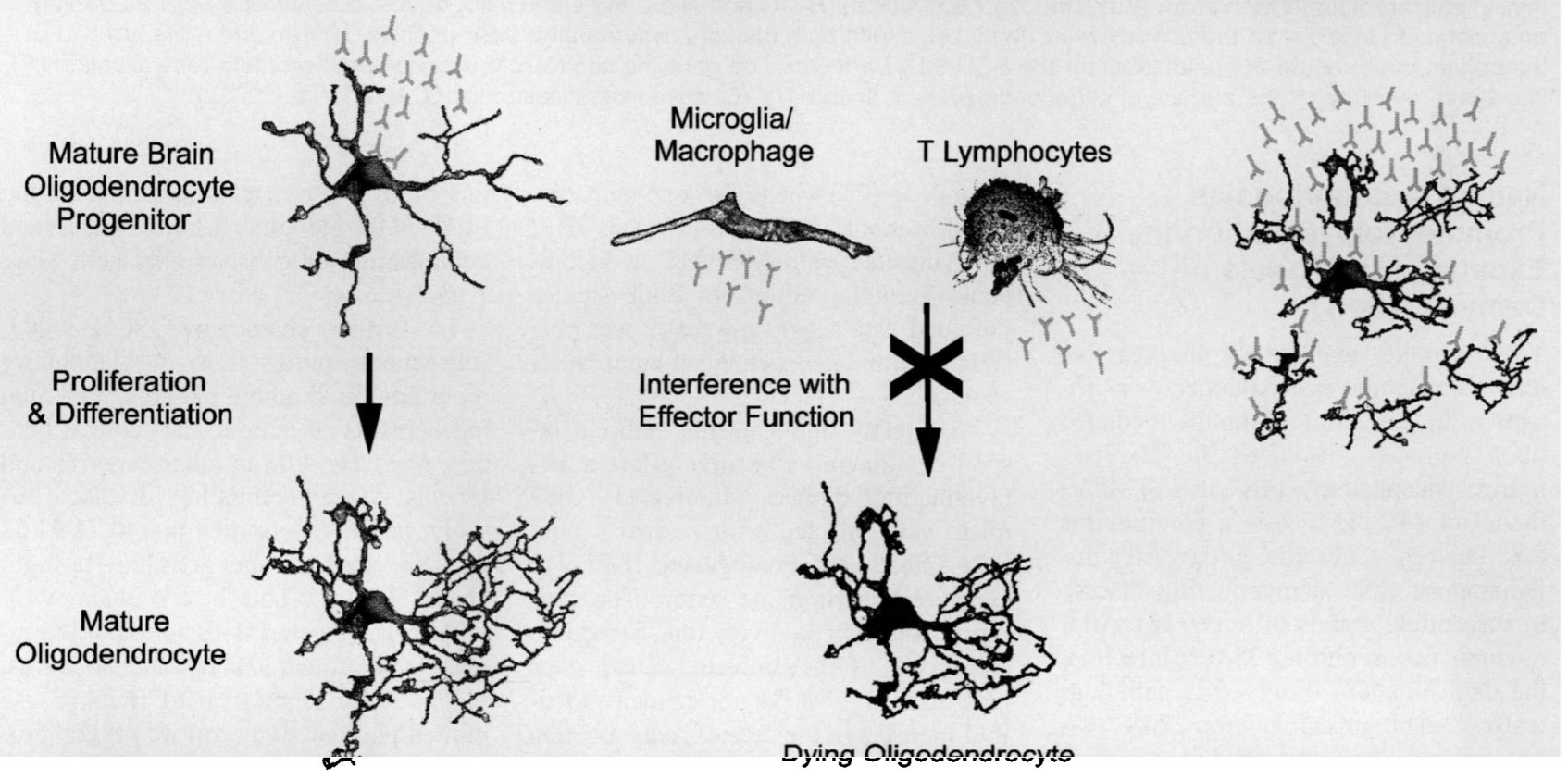

Fig. 2.

The schematic describes three potential mechanisms by which remyelination-promoting autoantibodies could function. In the direct hypothesis, it is proposed that autoantibodies reactive with the surface of oligodendrocytes could stimulate a receptor to induce the proliferation and differentiation of progenitors. The indirect hypotheses include modulation of the immune response or the opsonization of debris in the lesion. Autoantibodies could act by interfering with the effector function of a macrophage or T lymphocyte. Alternatively, polyreactive autoantibodies directed to the CNS may aid in the clearance of cellular debris, permitting the normal process of remyelination to proceed. This is referred to as the "scavenger" hypothesis and explains the broad antigen specificity of remyelinationpromoting autoantibodies toward both surface and intracellular proteins. 


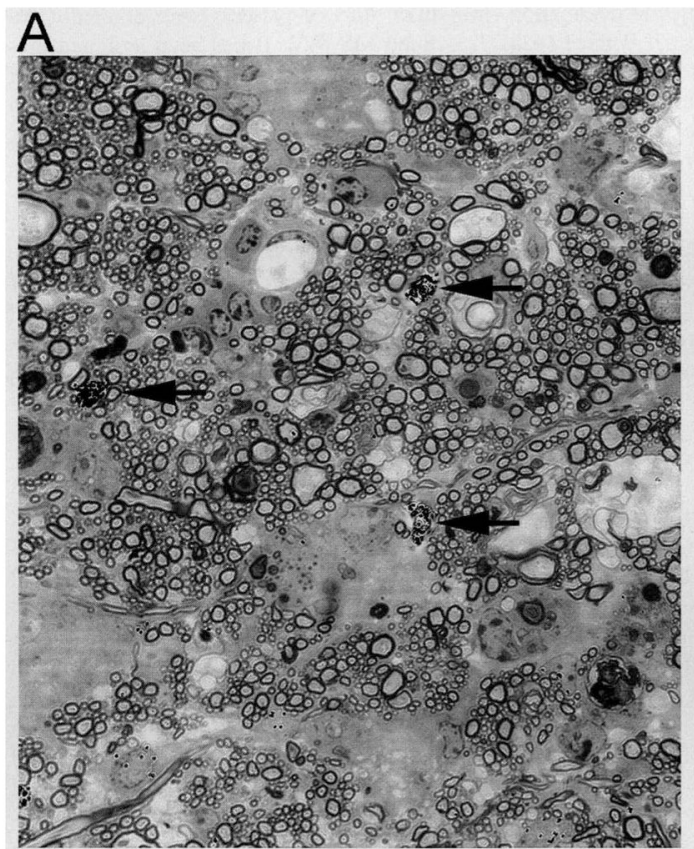

B

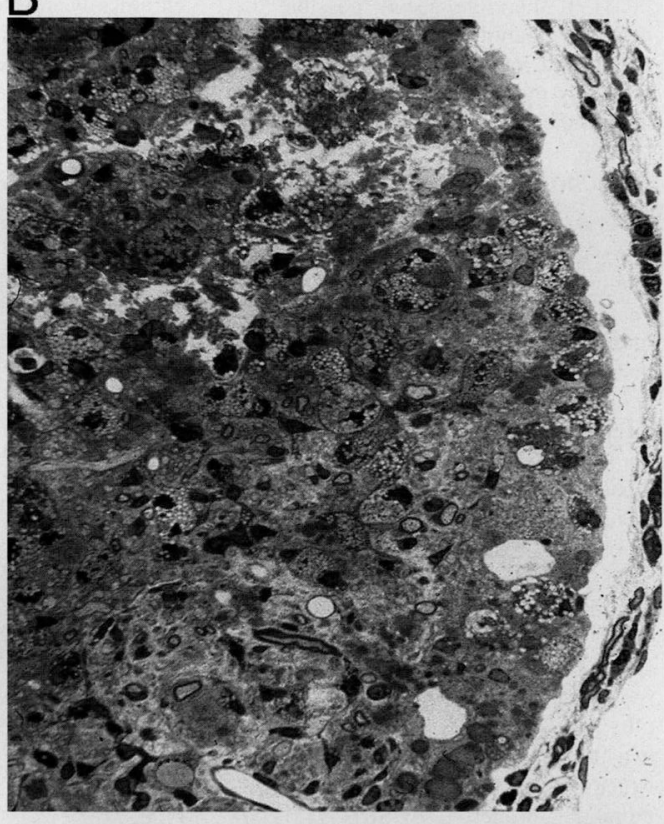

C

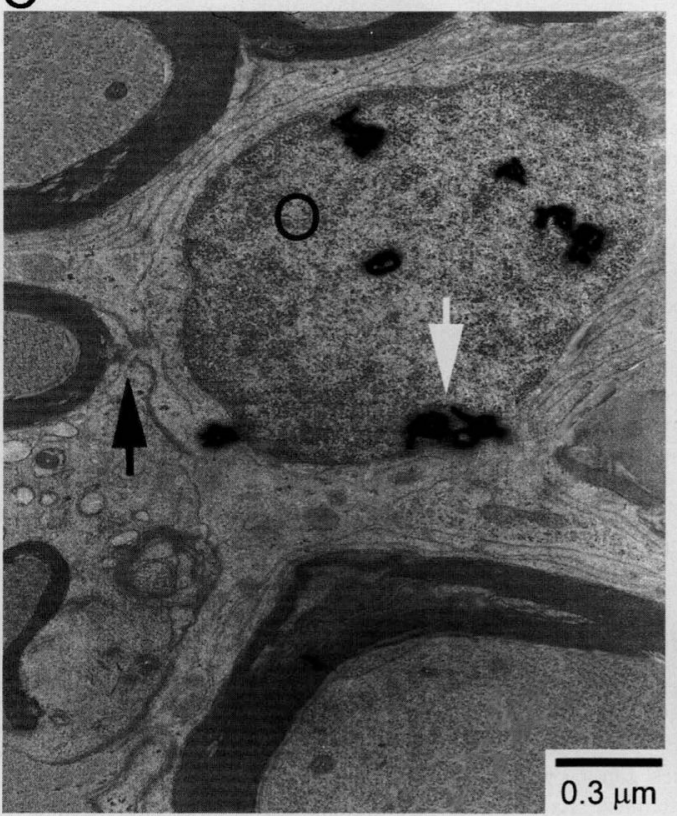

D

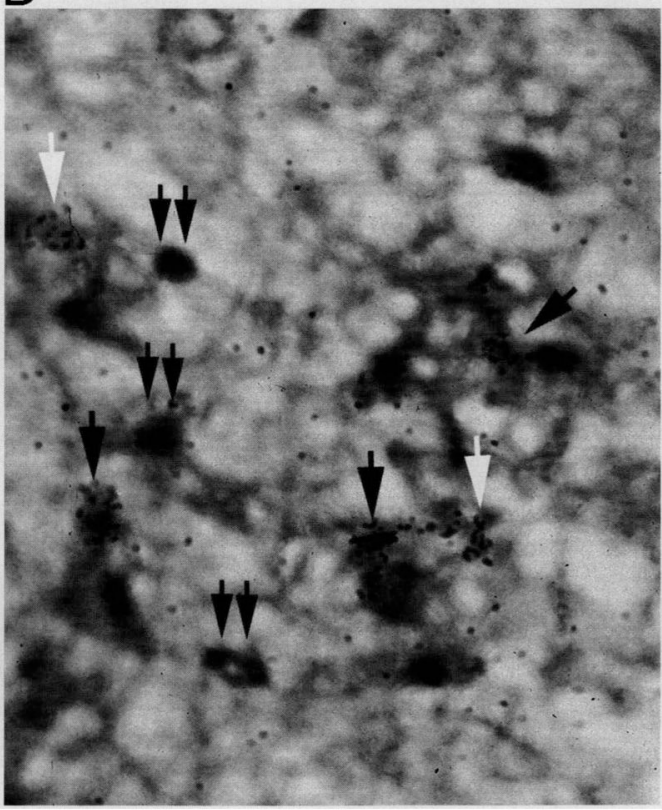

Fig. 3.

Proliferation of oligodendrocytes in remyelinating lesions after treatment with purified $\operatorname{IgG}$ directed against SCH. SJL/J mice chronically infected with Theiler's murine encephalomyelitis virus (TMEV) were treated twice weekly for 4-5 weeks ( $1 \mathrm{mg}$ total dose) with purified $\mathrm{IgG}$ directed against $\mathrm{SCH}(\mathrm{SCH} / \mathrm{IgG})(A, C, D)$ or $\mathrm{IgG}$ obtained from animals injected with phosphate-buffered saline (PBS) as a control $(\mathrm{PBS} / \mathrm{IgG})(B)$. Before sacrifice, an intraperitoneal injection of $\left[{ }^{3} \mathrm{H}\right]$ thymidine was given to aid in the localization of proliferating cells. After $\mathrm{SCH} / \mathrm{IgG}$ treatment, extensive spinal cord remyelination and proliferating cells (black arrows) were observed by light microscopy $(A)$, whereas extensive 
demyelination with little or no remyelination was observed in control mice treated with PBS/IgG $(B)$. Remyelination in $A$ is evidenced by many thinly myelinated axons in the field. (Original magnifications for $\mathrm{A}$ and $\mathrm{B}$ are $1,300 \times$ and $1,000 \times$, respectively.) To identify the proliferating cells in $\mathrm{SCH} / \mathrm{IgG}$ treated mice, electron microscopy $(C)$ and immunohistochemistry $(D)$ were used. $C$ shows an electron micrograph of a presumed oligodendrocyte (black $O$ ) that incorporated the $\left[{ }^{3} \mathrm{H}\right]$ thymidine label (white arrow) and is extending a process to myelinate a nearby axon (black arrow). (Original magnification for panel $\mathrm{C}$ is $14,000 \times)$. D shows three cells that have incorporated $\left[{ }^{3} \mathrm{H}\right]$ thymidine and are positive for the oligodendrocyte marker, galactocerebroside (GC) (single black arrows). However, there are cells in the lesion that have incorporated $\left[{ }^{3} \mathrm{H}\right]$ thymidine, but do not stain positively for GC (white arrows). Additionally, there are GC-positive cells that do not incorporate $\left[{ }^{3} \mathrm{H}\right]$ thymidine (double black arrows). Some of the unidentified, proliferating cells in the lesion may be of the oligodendrocyte lineage and may represent progenitors. (Original magnification for panel $D$ is $1,400 \times$.) 

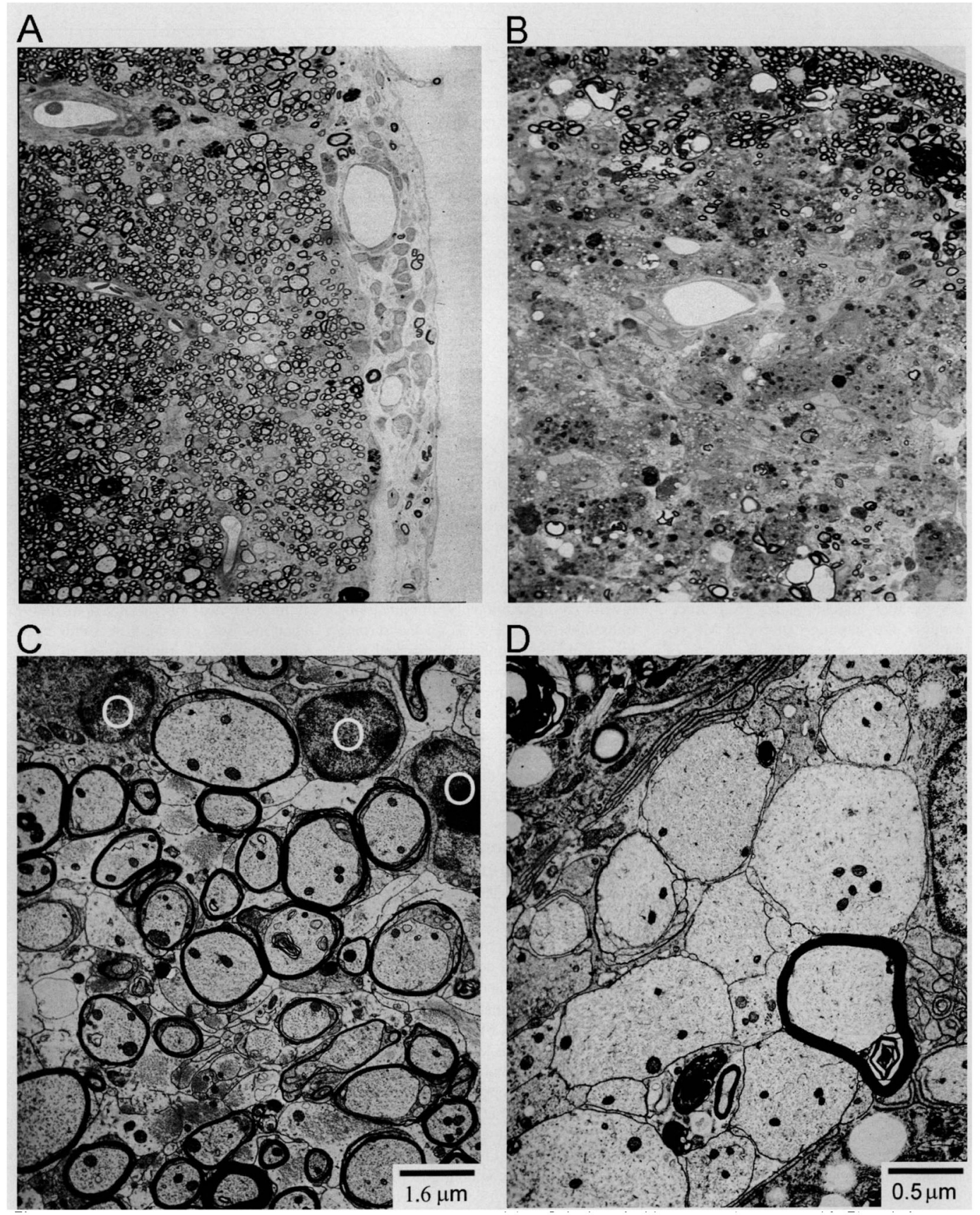

Fig. 4.

Promotion of remyelination by immunoglobulins reactive with MBP. Spinal cord white matter photographs $(A, B)$ and electron micrographs $(C, D)$ are shown for mice chronically infected with Theiler's murine encephalomyelitis virus (TMEV) and treated with affinitypurified immunoglobulin against myelin basic protein (MBP) $(\mathrm{MBP} / \mathrm{Ig})(A, C)$ or affinitypurified immunoglobulin against incomplete Freund's adjuvant (IFA/Ig) $(B, D)$ as a control. Chronically-infected SJL/J mice from both groups were injected twice a week for 4-5 weeks (total dose of $240 \mathrm{mg}$ ). After treatment with MBP/Ig, extensive remyelination was evident by both light $(A)$ and electron $(C)$ microscopy. Note the presence of the three 
oligodendrocytes (white $O$ ) in the remyelinated region $(C)$. In contrast, control mice treated with IFA/Ig showed extensive demyelination with minimal repair $(B, D)$. This is evident by both light $(B)$ and electron $(D)$ microscopy. (Original magnifications for panels $A-D$ are $1000 \times, 1000 \times, 2500 \times$, and $8000 \times$, respectively.) 